\title{
An Uncommon Complication of a Common Procedure
}

\author{
Demetrios N. Moris • Adamantios Michalinos • \\ Spiridon Vernadakis
}

Received: 31 March 2014 / Accepted: 27 April 2014 / Published online: 9 May 2014

(C) Association of Surgeons of India 2014

\begin{abstract}
Constant, safe and reliable endovascular access is necessary for patients' diagnosis and treatment. Endovascular access is possible with a variety of means, including central and peripheral venous catheters. Peripheral catheterization is an extremely common medical procedure and is considered risk-free or associated with minimal complications. Still potentially serious complications can occur. Authors describe a rare case of peripheral catheter migration at left pulmonary artery in an immunosuppressed patient.
\end{abstract}

Keywords Catheter tip $\cdot$ Migration $\cdot$ Emboli $\cdot$ Peripheral venous

\section{Image}

A 61-year-old man became febrile on the 8th postoperative day following renal transplantation from a deceased donor, $\left(\mathrm{T}=37.3^{\circ} \mathrm{C}\right)$. On clinical examination, he presented sensitivity and hardness at a 16 French Gauge peripheral venous catheter (PVC) insertion place in the right cephalic vein. The change was copious due to local inflammation, and catheter was extracted with a fraction of its tip. The tip was not traceable by palpation. The patient remained febrile $\left(\mathrm{T}=37.4{ }^{\circ} \mathrm{C}\right)$ but local hardness and pain subsided. Laboratory tests were unremarkable. Two days later, the patient had a routine chest $X$-ray after hemodialysis (Fig. 1). X-ray showed a linear radioopaque shadow of the left lung (Fig. 2), consistent with migration of catheter tip upward into a segmental branch of

D. N. Moris $\cdot$ A. Michalinos $\cdot$ S. Vernadakis

Transplantation Unit, Laikon General Hospital, University of Athens,

Athens, Greece

A. Michalinos ( $\square)$

4th floor, Agiou Thoma 17 str., Goudi, Athens 11527, Greece

e-mail: amichalinos@hotmail.com

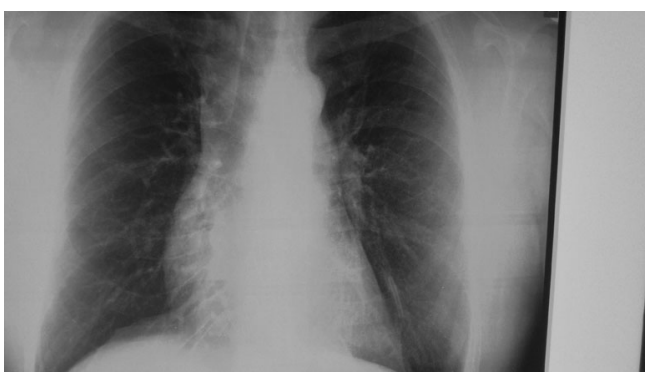

Fig. 1 Chest X-ray demonstrating peripheral venous catheter at left pulmonary artery

the left pulmonary artery. No further intervention was decided. Fever was attributed to urinary tract infection related to Foley catheter and was treated by antibiotics. At 1-month follow-up visit, the patient remains asymptomatic and normoxic.

A variety of complications including the relatively common phlebitis, infections and extravasation of fluids and uncommon ones like migration are connected to venous

Fig. 2 Magnification demonstrating the precise embolization site

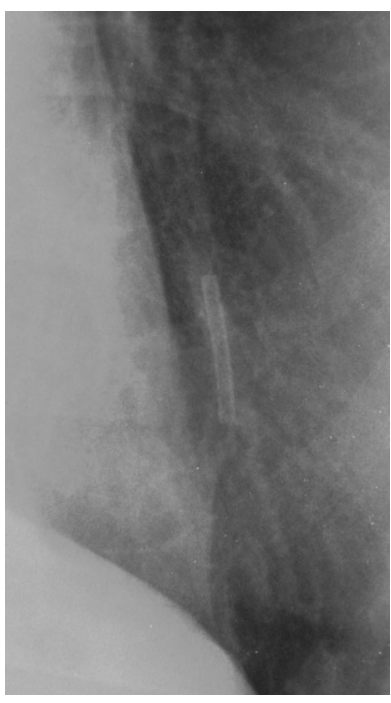


catheterization [1]. While complications in terms of severity and frequency are vigorously described in central venous catheters [2], data are sparse other peripheral venous catheter. The risk of serious complications in catheter embolism is unknown. High-risk anatomic regions include the intracardiac area, while risk is lower in the vena cava, and the lowest if the embolus is located in the pulmonary artery. Catheter embolism may remain undiagnosed for a prolonged period and can be found incidentally. If conservative management is opted, a sequential radiographic follow-up is essential even in asymptomatic patients to prevent potentially life threatening complications in future from catheter further migration. In case removal is considered necessary based on symptoms or deterioration of blood gases, available methods include snares, biopsy forceps, baskets, pigtail catheters and surgical intervention [3].

\section{References}

1. Singh S, Prakash J, Shukla VK, Singh LKS (2010) Intravenous catheter associated complications. J Assoc Physicians India 58:194 196

2. Amerasekera SSH, Jones CM, Patel R, Cleasby MJ (2009) Imaging of the complications of peripherally inserted central venous catheters. Clin Radiol 64(8):832-840

3. Strohmer B, Altenberger J, Pichler M (2012) A new approach of extracting embolized venous catheters using a large-diameter steerable sheath under biplane fluoroscopy. Clin Imaging 36(5):502-508 